\title{
Prevalence of major structures injury in thyroid and neck surgeries: a national perspective
}

\author{
Zaid Al-Qurayshi ${ }^{1}$, Christopher Blake Sullivan ${ }^{1}$, Nitin Pagedar ${ }^{1}$, Gregory Randolph ${ }^{2,3}$, Emad Kandil ${ }^{4}$ \\ ${ }^{1}$ Department of Otolaryngology - Head \& Neck Surgery, University of Iowa Hospitals and Clinics, Iowa City, IA, USA; ${ }^{2}$ Department of \\ Otolaryngology - Head and Neck Surgery, Harvard Medical School, Boston, MA, USA; ${ }^{3}$ Division of Thyroid and Parathyroid Endocrine Surgery, \\ Massachusetts Eye and Ear Infirmary, Surgical Oncology, Massachusetts General Hospital, Boston, MA, USA; ${ }^{4}$ Department of Surgery, Tulane \\ University School of Medicine, New Orleans, LA, USA \\ Contributions: (I) Conception and design: All authors; (II) Administrative support: Z Al-Qurayshi, E Kandil; (III) Provision of study materials or \\ patients: Z Al-Qurayshi, E Kandil; (IV) Collection and assembly of data: Z Al-Qurayshi, CB Sullivan, E Kandil; (V) Data analysis and interpretation: \\ All authors; (VI) Manuscript writing: All authors; (VII) Final approval of manuscript: All authors. \\ Correspondence to: Emad Kandil, MD, MBA, FACS. Tulane School of Medicine, Department of Surgery, 1430 Tulane Ave, SL-22, New Orleans, LA \\ 70112, USA. Email: ekandil@tulane.edu.
}

Background: The objectives of the study is to examine the prevalence and burden of major structures injury (pharynx, esophagus, trachea, larynx, lymphatic, vessels \& nerves) in patients who underwent thyroid, parathyroid, and neck dissection surgeries in the United States.

Methods: The study is a retrospective cross-sectional analysis utilizing the Nationwide Readmissions Database, 2010-2015. The study population included adults ( $\geq 18$ years) patients who underwent thyroid, parathyroid, and neck dissection surgeries.

Results: A total of 54,443 patients were included. Major structures injury was reported in $221(0.48 \%)$ patients. The injured structures were vascular $(0.22 \%)$, lymphatic $(0.18 \%)$, pharynx/esophagus $(0.06 \%)$, neural $(0.03 \%)$, and trachea/larynx $(0.002 \%)$. The risk of injury increased annually during the study period (OR: 1.29, 95\% CI: 1.16, 1.44, $\mathrm{P}<0.001$ ). The risk of injury was highest in patients who underwent thyroidectomy with neck dissection $(1.01 \%)$ or neck dissection alone $(1.81 \%)(\mathrm{P}<0.001$ each). The risk was also highest for patients with a head and neck cancer diagnosis (OR: 1.80, 95\% CI: 1.24, 2.61, P=0.002). Patients with those injuries had a higher prevalence of blood transfusion $(2.82 \%$ vs. $0.17 \%)$, postoperative fistula $(3.10 \%$ vs. $0.03 \%$ ), readmission $(28.90 \%$ vs. $3.59 \%)$, and postoperative mortality $(0.87 \%$ vs. $0.06 \%)$ $(\mathrm{P}<0.05$ each). Management of patients with those injuries was associated with a longer hospital stay by $4.86 \pm 0.48$ days $(\mathrm{P}<0.001)$, and a higher cost by $\$ 16,151.00 \pm 173.36(\mathrm{P}<0.001)$.

Conclusions: Injuries of major structures in thyroid and neck surgeries are more prevalent in cancer patients. There has been a recent increase in the risk of such injuries in the United States. Those injuries are associated with significant clinical and economic burden.

Keywords: Head and neck surgery; nerve injury; chyle leak; esophagus injury; vascular injury

Submitted Mar 18, 2020. Accepted for publication Oct 21, 2020.

doi: $10.21037 /$ gs-20-369

View this article at: http://dx.doi.org/10.21037/gs-20-369

\section{Introduction}

Currently, there is an estimated 234 million operations being performed globally on a yearly basis (1). As the amount and complexity of procedures increases, emerging research has been focusing on surgical safety and clinical outcomes. Intraoperative iatrogenic injuries can be inconsequential, while others can result in a grave morbidity and mortality. In 2012, over one trillion dollars were spent 
on intragenic medical complications $(2,3)$. The associated morbidity with surgical injurie is harder to quantify, but nevertheless the consequences can be devastating (4). Prior studies have suggested that at least half to two-thirds of all complications associated with surgeries are avoidable $(1,5,6)$. Increasing evidence supports that a surgeon's expertise and procedure volume is associated with favorable clinical outcomes (7-9).

We have previously shown that $0.3 \%$ of all surgicalrelated injuries were due to procedures performed in the ear, nose, mouth, and pharynx (10). In a survey of 466 members of the American Academy of OtolaryngologyHead and Neck Surgery, reported errors were the result of technical misadventure $19.3 \%$ of the time (4). Neck dissection, thyroid surgery, and parathyroid surgery are commonly performed procedures and not without considerable inherent risks. Iatrogenic injuries during these procedures can cause functional impairment and potentially impact disease survival (11). The prevalence of major structure injury for these procedures is not well described at the national level. The objective of the present study was to identify the prevalence of major structure injury following neck dissections, thyroid, and parathyroid surgeries. We also aimed to identify the associated risk factors and the associated burden at the national level. We present the following article in accordance with the "STrengthening the Reporting of OBservational studies in Epidemiology" reporting checklist (available at http://dx.doi.org/10.21037/ gs-20-369).

\section{Methods}

This study is a retrospective cross-sectional analysis utilizing the Nationwide Readmissions Database (NRD) for the years 2010-2015 (12). The NRD is a part of the Healthcare Cost and Utilization Project (HCUP), sponsored by the Agency for Healthcare Research and Quality (12). The NRD is a unique and powerful database designed to support various types of analyses of national readmission rates for all payers and the uninsured (12). The database includes discharge data from 27 geographically dispersed states, accounting for $57.8 \%$ of the total U.S. resident population and $56.6 \%$ of all U.S. hospitalizations (12). Additionally, the database allows for weighted analysis that has been utilized in this project to provide a better estimation of national outcomes (12). The NRD tracks patients across the sampled hospitals within a calendar year for any readmission (12). This database addresses a large gap in health care data - the lack of nationally representative information on hospital readmissions for all ages (12). The NRD consists of publicly available de-identified data that does not meet the criteria of human subject research and does not meet the criteria for review by the University of Iowa Institutional Review Board. The study was conducted in accordance with the Declaration of Helsinki (as revised in 2013).

The main objectives of the study are to examine the prevalence of and the associated outcomes with major structure injuries reported in patients admitted for thyroid, parathyroid, or neck dissection surgery. A major structure injury was defined using the International classification of diseases, $9^{\text {th }}$ edition, codes (ICD-9) and included: vascular injuries (ICD-9: 900, 904.9, 998.11), trachea/larynx (ICD-9: 807.5, 807.6, 874.0), pharynx/esophagus injuries (ICD-9: 478.29, 530.4), lymphatic injury (ICD-9: 457.8), and neural injuries (ICD-9: 957.9, 957.0, 951.4, 951.6, 951.7, 951.8, $951.9,953.4)$. All those codes indicate injury that was not part of the planned resection and they also refer to visible damage that could be encountered intraoperatively and does not include physiological injuries such as nerve stretching or a simple postoperative hematoma. Thyroid, parathyroid, and neck dissection surgeries were identified using the following ICD-9 codes: 06.2, 06.3, 06.4, 06.6, 06.7, 06.8, 40. All admissions were checked for completeness of data. Admissions with missing values for the study parameters were excluded.

Outcomes of interest included: (I) risk of requiring blood transfusion (not reported, reported), (II) risk of requiring tracheostomy (not reported, reported), (III) risk of readmission within 30 days postoperatively, (IV) risk of postoperative mediastinitis (ICD-9: 519.2) within 30 days, (V) risk of postoperative subcutaneous emphysema (ICD-9: 998.81) within 30 days, (VI) risk of postoperative fistula (ICD-9: 998.6) within 30 days, it should be noted the used code does not specify the type of fistula but indicates it developed postoperatively (VII) inpatient mortality risk within 30 days postoperatively, (VIII) total length of hospital stay in days, and (IX) cost of health services provided during the admission-the database includes hospital charges associated with each admission as well as cost-to-charge ratio determined for each hospital that allows conversion of charges values to cost values, all cost values were adjusted for inflation rate to reflect 2018 U.S dollar value using Bureau of Labor Statistics inflation calculator $(12,13)$.

The independent factors that were assessed for their association with the risk of injury included: (I) age: $18-<45,45-55,55-65, \geq 65$ years; (II) gender: male, 
female; (III) modified Charlson comorbidity index score (CCIS), classified into: 0, 1, $\geq 2$ (14); (IV) Overweight: not reported, reported; (V) tobacco use history: not reported, reported; (VI) Diagnosis: cancer, benign, toxic thyroid disease, parathyroid disease; (VII) type of surgery: thyroid lobectomy, total thyroidectomy, parathyroidectomy, neck dissection, thyroidectomy with neck dissection; (VIII) hospital volume defined as the number of surgeries performed in each hospital per year, classified by applying quartile classification with rounding to the nearest 10 to avoid introducing bias, the classification included: lowvolume hospitals ( $<25$ th percentile: $1-20$ surgeries/yr), intermediate-volume hospitals $(25$ th $-<75$ th percentiles: 21-100 surgeries/yr.), high-volume hospitals ( $\geq 75$ th percentile: $\geq 101$ surgeries/yr.); (IX) Location and type of hospital as coded in the database into: metropolitan nonteaching, metropolitan teaching, non-metropolitan (12).

\section{Statistical analysis}

Statistical analysis used weighted data to reflect national estimates. The records' weights are available in the NRD and calculated based on the stratification variables that were used in the sampling methodology (12). Cross-tabulation and Chi-square test were used to examine the association between each of the independent factors and the risk of injury. Variables that demonstrated a significant association with the outcomes were considered possible confounders and were included in multivariate logistic regression models. Multivariate logistic regression models were used to estimate the risk of having the injury and the risk the study outcomes. Multivariate linear regression models were used to compare means of hospital length of stay and cost of health services between the study groups while controlling for confounders. Significance level was set as $(\alpha=0.05)$. All data analyses were performed using SAS 9.4 for Windows (SAS Institute Inc., Cary, NC, USA). The authors are accountable for all aspects of the work in ensuring that questions related to the accuracy or integrity of any part of the work are appropriately investigated and resolved.

\section{Results}

A total of 54,443 patients were included. Major structures injuries were reported in $189(0.48 \%)$ patients (Tables 1,2$)$. The injured structures were vascular $(0.22 \%)$, lymphatic $(0.18 \%)$, pharynx/esophagus $(0.06 \%)$, neural $(0.03 \%)$, and trachea/larynx $(0.002 \%)$. The risk of injury increased annually during the study period [OR: $1.29,95 \%$ CI: $1.16-$ 1.44, $\mathrm{P}<0.001]$.

Patients who experienced major structures injuries tended to be older ( $\geq 55$ years), with multiple comorbidities, and being treated in a teaching hospital, however, none of those factors was significantly associated with the risk of injury in the multivariate logistic regression model (Table 3). Two clinical factors were significantly associated with the risk of injury: diagnosis of head and neck cancer (OR: 1.80, 95\% CI: 1.24-2.61, $\mathrm{P}=0.002)$ and neck dissection whether as the only procedure (OR: $7.02,95 \%$ CI: 4.43-11.15, $\mathrm{P}<0.001)$ or in conjunction with a thyroid surgery (OR: 3.64, 95\% CI: 2.11-6.30, $\mathrm{P}<0.001)$.

Patients with those injuries had a higher prevalence of blood transfusion $(2.82 \%$ vs. $0.17 \%)$, postoperative fistula (3.10\% vs. $0.03 \%)$, readmission $(28.90 \%$ vs. $3.59 \%)$, and postoperative mortality $(0.87 \%$ vs. $0.06 \%)(\mathrm{P}<0.05$ each $)$ (Table 4). There was no reported mediastinitis in both cases and controls, and the risk of requiring tracheostomy and developing subcutaneous emphysema were not statistically significant (Table 4). Management of patients with those injuries was associated with a longer hospital stay by $4.86 \pm 0.48$ days $(\mathrm{P}<0.001)$, and a higher cost by $\$ 16,151.00 \pm 173.36(\mathrm{P}<0.001)$.

\section{Discussion}

Over the last few decades, surgical checklists and protocols have been put in place to help reduce operative complications (15). In the present study, we found there is an upward trend in the risk of major structures injury in patients who underwent neck dissection, thyroid, and parathyroid surgeries. We have demonstrated that vascular, neural, and visceral injuries occur more often in cancer patients and when neck dissection is performed. We also found that these unfortunate incidents were associated with an increased risk of postoperative complications, blood transfusion, longer hospital stay, overall cost, readmission, and even mortality.

Neck dissection with or without thyroidectomy was strongly associated with the risk of a major structure injury compared to a parathyroidectomy, hemithyroidectomy or total thyroidectomy alone. There is a paucity of published data on the risk of iatrogenic intraoperative injuries during neck dissection versus a neck dissection with thyroidectomy. An analysis by Teymoortash et al. of 98 patients who had selective neck dissection, there were four incidents of internal jugular vein resection, and two incidents of 
Table 1 Descriptive statistics of the study population, National Readmission Database, 2010-2015

\begin{tabular}{|c|c|c|c|c|}
\hline & $\begin{array}{l}\text { Sample population, } \\
\text { (\%) }(\mathrm{N}=54,443)\end{array}$ & \multicolumn{3}{|c|}{ Intraoperative major structure injury (\%) } \\
\hline Age (yr.) & & & & 0.39 \\
\hline $18-<45$ & 26.45 & 26.48 & 20.76 & \\
\hline $45-<55$ & 21.74 & 21.75 & 20.84 & \\
\hline$\geq 65$ & 28.65 & 28.63 & 31.80 & \\
\hline Gender & & & & $<0.001$ \\
\hline Male & 27.11 & 26.96 & 58.87 & \\
\hline Female & 72.89 & 73.04 & 41.13 & \\
\hline 1 & 34.84 & 34.85 & 32.07 & \\
\hline$\geq 2$ & 22.22 & 22.07 & 53.62 & \\
\hline Overweight & & & & 0.30 \\
\hline Not reported & 87.58 & 87.59 & 84.82 & \\
\hline Reported & 12.42 & 12.41 & 15.18 & \\
\hline Tobacco use history & & & & 0.024 \\
\hline Not reported & 90.48 & 90.51 & 85.07 & \\
\hline Reported & 9.52 & 9.49 & 14.93 & \\
\hline Parathyroid disease & 10.44 & 10.49 & 0.28 & \\
\hline Surgery & & & & $<0.001$ \\
\hline Thyroid lobectomy & 27.54 & 27.62 & 11.22 & \\
\hline Total thyroidectomy & 36.94 & 37.06 & 12.73 & \\
\hline Parathyroidectomy & 12.29 & 12.35 & 0.80 & \\
\hline Neck dissection & 15.41 & 15.21 & 58.68 & \\
\hline Thyroidectomy and neck dissection & 7.82 & 7.77 & 16.57 & \\
\hline
\end{tabular}

${ }^{\mathrm{a}}$, Chi-square test. CCIS, Charlson comorbidity index score.

lymphatic duct injury (16).

In this study, patients who had a major structure injury were more likely to have a longer hospital stay and be readmitted within 30 days of the procedure. An analysis of 990 patients after thyroid surgery in the NRD found calcium and mineral metabolism disorders to be the main reasons for readmission (17). These sequelae of complications can lead to a significant financial burden for the patient and hospital (18). New healthcare policies are emerging that place the increased costs associated with 
Table 2 Descriptive statistics of the study population, National Readmission Database, 2010-2015

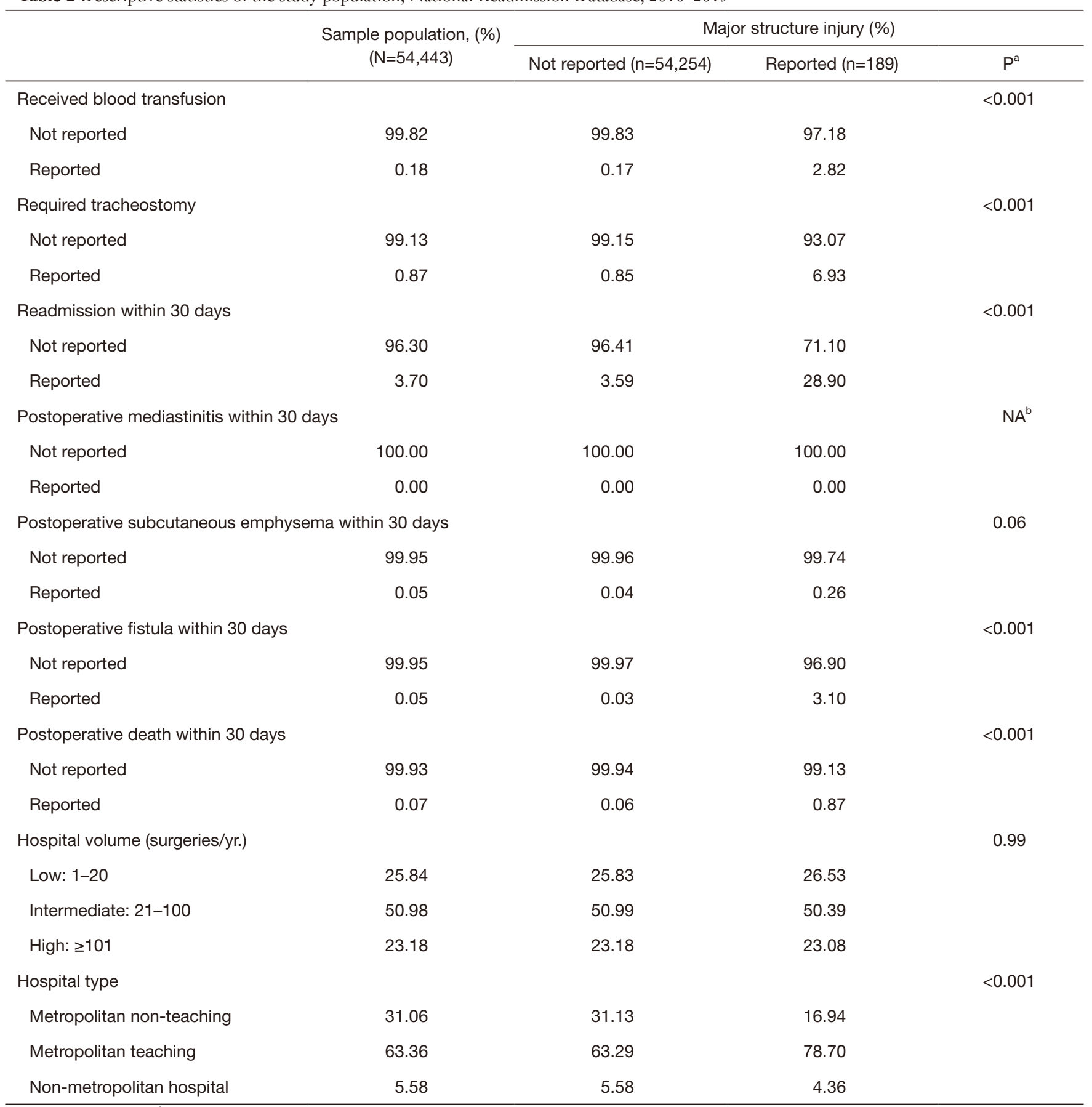

${ }^{\mathrm{a}}$, Chi-square test; ${ }^{\mathrm{b}}$, not applicable because there is no reported event.

complications on the hospital, physician, and acute care services (19).

In the present study, patients were more likely to need a blood transfusion, and the risk of additional procedures such as a tracheostomy tended to be higher. These secondary procedures, such as a blood transfusion, and postoperative complication can further complicate the recovery course and be life-threatening (20). The impact of major complications could extend beyond the immediate postoperative period. The current study does not have 
Table 3 Risk of intraoperative major structure injury in patients underwent thyroid and neck head and neck surgeries in relation to clinical and demographic factors

\begin{tabular}{|c|c|c|c|c|}
\hline & Risk of injury (\%) & $\mathrm{OR}^{\mathrm{a}}$ & $95 \% \mathrm{Cl}$ & $\mathrm{P}$ \\
\hline Male & 1.03 & 1.75 & $1.23,2.48$ & 0.002 \\
\hline Female & 0.27 & Reference & & \\
\hline \multicolumn{5}{|l|}{ CCIS } \\
\hline 1 & 0.44 & 0.98 & $0.61,1.59$ & 0.94 \\
\hline$\geq 2$ & 1.15 & 1.31 & $0.80,2.16$ & 0.28 \\
\hline \multicolumn{5}{|l|}{ Tobacco use history } \\
\hline Not reported & 0.45 & Reference & & \\
\hline Cancer & 1.02 & 1.80 & $1.24,2.61$ & 0.002 \\
\hline Benign & 0.31 & Reference & & \\
\hline Toxic thyroid disease & 0.24 & 1.61 & $0.79,3.28$ & 0.19 \\
\hline Parathyroid disease & 0.01 & 0.118 & $0.01,2.57$ & 0.17 \\
\hline \multicolumn{5}{|l|}{ Surgery } \\
\hline Thyroid lobectomy & 0.19 & 1.36 & $0.76,2.43$ & 0.30 \\
\hline Total thyroidectomy & 0.16 & Reference & & \\
\hline Parathyroidectomy & 0.03 & 0.76 & $0.10,5.75$ & 0.79 \\
\hline Non-metropolitan hospital & 0.37 & 1.50 & $0.68,3.29$ & 0.31 \\
\hline
\end{tabular}

${ }^{a}$, the model includes all the factors listed in the table; ${ }^{b}$, not applicable because no reported injury in patients with parathyroid disease.

OR, adjusted odds ratio; $\mathrm{Cl}$, confidence interval; CCIS, Charlson comorbidity index score.

a long-term follow-up, however previous studies have demonstrated that injuries such as vocal cord paralysis and permanent hypoparathyroidism were associated with an increased risk of respiratory infection and mortality, respectively $(21,22)$.

We found that major structure injuries tend to be higher in teaching hospitals, however this risk was not statistically significant. Large teaching hospitals more often treat patients with complicated presentation and past medical history, and perform complex and innovative procedures, with the involvement of education and participation of residents and fellows. Previous studies have examined surgical outcomes at teaching hospitals with mixed results (23-30). A study of 2,320,920 otolaryngology patients from the National Surgical Quality Improvement Program database found that resident involvement did not increase the risk of morbidity and mortality (23). Additionally, research has shown that complications are lessened 
Table 4 Risk of selected postoperative outcomes based on whether the patient experienced intraoperative major structure injury

\begin{tabular}{|c|c|c|c|c|c|}
\hline Outcome & $\begin{array}{l}\text { Major structure } \\
\text { injury }\end{array}$ & $\begin{array}{l}\text { \% outcome/ } \\
\text { Mean (SEM) }\end{array}$ & $\mathrm{OR}^{\mathrm{a}}$ & $95 \% \mathrm{Cl}$ & $P$ \\
\hline Blood transfusion & Not reported & 0.17 & Reference & & \\
\hline Required tracheostomy & Not reported & 0.85 & Reference & & \\
\hline $\begin{array}{l}\text { Postoperative subcutaneous emphysema } \\
\text { within } 30 \text { days }\end{array}$ & Reported & 0.26 & 2.66 & $0.30,23.33$ & 0.38 \\
\hline \multirow[t]{2}{*}{ Postoperative fistula within 30 days } & Not reported & 0.03 & Reference & & \\
\hline & Reported & 3.10 & 34.29 & $5.96,197.49$ & $<0.001$ \\
\hline Postoperative death within 30 days & Reported & 0.87 & 4.70 & $1.07,20.65$ & 0.040 \\
\hline \multirow[t]{2}{*}{ Length of stay (days) } & Not reported & $2.16(0.01)$ & & & Reference $^{\mathrm{b}}$ \\
\hline & Reported & $7.02(0.48)$ & & & $<0.001^{\mathrm{b}}$ \\
\hline \multirow[t]{2}{*}{ Cost (\$) } & Not reported & $12,170.00(28.71)$ & & & Reference $^{\mathrm{b}}$ \\
\hline & Reported & $28,321.00(176.18)$ & & & $<0.001^{\mathrm{b}}$ \\
\hline
\end{tabular}

\footnotetext{
${ }^{\text {a }}$, logistic regression model includes: age (only tracheostomy model), gender (except emphysema model), Charlson comorbidity index score, weight status (only mortality, readmission models), tobacco use status (only readmission, tracheostomy, transfusion, mortality models), diagnosis (all models), type of surgery (all models), and hospital teaching type (tracheostomy, transfusion models); ${ }^{b}$, linear regression model includes: age, gender, Charlson comorbidity index score, weight status, tobacco use status, diagnosis, type of surgery, hospital volume, and hospital teaching type. OR, adjusted odds ratio; Cl, confidence interval; SEM, standard error of the mean.
}

when performed at high-volume centers and by high volume surgeons $(8,30)$. Our findings are most probably a reflection that more complications occur at large teaching hospitals due to the increasing complexity of procedures that are performed at these institutions compared to nonmetropolitan teaching hospitals.

This retrospective epidemiological analysis is not without inherent limitations. The analysis of the NRD database coding system is subject to misclassification errors. Causality cannot be inferred as the study is a retrospective crosssectional analysis. Information in the NRD is collected from administrative data and does include extensive clinical details such as history of neck irradiation, neck dissection levels, staging, diagnostic studies, available resources, and reason for readmission. The NRD also lacks information regarding the severity of those injuries and what measures being implanted in their management. Nevertheless, the database is fit for a general epidemiological examination of the prevalence and outcomes of major structures injuries at the national level that no other resource could provide and could ultimately guide the direction of clinically-oriented studies. We believe that our data provides a epidemiological analysis of the prevalence, clinical burden, and financial burden of major structures injuries in head and neck surgery.

\section{Conclusions}

In patients undergoing thyroid, parathyroid, and neck dissection procedures, the risk of major structures injuries are considerable and appears to be annually increasing at the national level. Those injuries are more prevalent in 
head and neck cancer patients, and during procedures that included a neck dissection. Those injuries are associated with a significant clinical and economic burden.

\section{Acknowledgments}

The study was selected for a podium presentation at $123 \mathrm{rd}$ annual meeting of the American Academy of Otolaryngology - Head \& Neck Surgery held in New Orleans, LA on September 17th, 2019.

Funding: None.

\section{Footnote}

Reporting Checklist: The authors have completed the STROBE reporting checklist. Available at http://dx.doi. org/10.21037/gs-20-369

Conflicts of Interest: All authors have completed the ICMJE uniform disclosure form. Emad Kandil serves as an unpaid Editorial-in-Chief of Gland Surgery. Gregory W. Randolph serves as an unpaid editorial board member of Gland Surgery from April 2019 to March 2021. Al-Qurayshi is supported by National Institutes of Health - Institutional National Research Award: T32 (\#5T32DC000040). The other authors have no conflicts of interest to declare.

Ethical Statement: The authors are accountable for all aspects of the work in ensuring that questions related to the accuracy or integrity of any part of the work are appropriately investigated and resolved. The study was conducted in accordance with the Declaration of Helsinki (as revised in 2013).

Open Access Statement: This is an Open Access article distributed in accordance with the Creative Commons Attribution-NonCommercial-NoDerivs 4.0 International License (CC BY-NC-ND 4.0), which permits the noncommercial replication and distribution of the article with the strict proviso that no changes or edits are made and the original work is properly cited (including links to both the formal publication through the relevant DOI and the license). See: https://creativecommons.org/licenses/by-nc-nd/4.0/.

\section{References}

1. Haynes AB, Weiser TG, Berry WR, et al. A surgical safety checklist to reduce morbidity and mortality in a global population. N Engl J Med 2009;360:491-9.

2. Andel C, Davidow SL, Hollander M, et al. The economics of health care quality and medical errors. J Health Care Finance 2012;39:39-50.

3. Makary MA, Daniel M. Medical error-the third leading cause of death in the US. BMJ 2016;353:i2139.

4. Shah RK, Kentala E, Healy GB, et al. Classification and consequences of errors in otolaryngology. Laryngoscope 2004;114:1322-35.

5. Kable AK, Gibberd RW, Spigelman AD. Adverse events in surgical patients in Australia. Int J Qual Health Care 2002;14:269-76.

6. Gawande AA, Thomas EJ, Zinner MJ, et al. The incidence and nature of surgical adverse events in Colorado and Utah in 1992. Surgery. 1999;126:66-75.

7. Al-Qurayshi Z, Robins R, Hauch A, et al. Association of Surgeon Volume With Outcomes and Cost Savings Following Thyroidectomy: A National Forecast. JAMA Otolaryngol Head Neck Surg 2016;142:32-9.

8. Kandil E, Noureldine SI, Abbas A, et al. The impact of surgical volume on patient outcomes following thyroid surgery. Surgery 2013;154:1346-52; discussion 1352-3.

9. Gourin CG, Tufano RP, Forastiere AA, et al. Volumebased trends in thyroid surgery. Arch Otolaryngol Head Neck Surg 2010;136:1191-8.

10. Al-Qurayshi Z, Randolph G, et al. A national overview of surgical misadventures in head and neck surgery: "Oh No, You Cut It". Laryngoscope 2020;130:918-24.

11. Harréus U. Surgical errors and risks - the head and neck cancer patient. GMS Curr Top Otorhinolaryngol Head Neck Surg 2013;12:Doc04.

12. Healthcare Cost and Utilization Project (HCUP). Overview of the nationwide readmissions database (NRD). Available online: https://www.hcup-us.ahrq.gov/ nrdoverview.jsp

13. Bureau of Labor Statistics. Databases, tables \& calculators by subject: Consumer price index. United States Department of Labor Web site. Available online: http:// www.bls.gov/data

14. Quan H, Sundararajan V, Halfon P, et al. Coding algorithms for defining comorbidities in ICD-9-CM and ICD-10 administrative data. Med Care 2005;43:1130-9.

15. Helmiö P, Blomgren K, Lehtivuori T, et al. Towards better patient safety in otolaryngology: characteristics of patient injuries and their relationship with items on the WHO Surgical Safety Checklist. Clin Otolaryngol 2015;40:443-8.

16. Teymoortash A, Hoch S, Eivazi B, et al. Postoperative morbidity after different types of selective neck dissection. 
Laryngoscope 2010;120:924-9.

17. Rios-Diaz AJ, Zheng R, Thibault DP, et al. Understanding nationwide readmissions after thyroid surgery. Surgery 2019;165:423-30.

18. Landais A, Morel M, Goldstein J, et al. Evaluation of financial burden following complications after major surgery in France: Potential return after perioperative goal-directed therapy. Anaesth Crit Care Pain Med 2017;36:151-5.

19. Healy MA, Mullard AJ, Campbell DA, et al. Hospital and Payer Costs Associated With Surgical Complications. JAMA Surg 2016;151:823-30.

20. Oldham J. Blood transfusion sampling and a greater role for error recovery. Br J Nurs 2014;23:S28-34.

21. Almquist M, Ivarsson K, Nordenstrom E, et al. Mortality in patients with permanent hypoparathyroidism after total thyroidectomy. Br J Surg 2018;105:1313-8.

22. Nouraei SAR, Allen J, Kaddour H, et al. Vocal palsy increases the risk of lower respiratory tract infection in low-risk, low-morbidity patients undergoing thyroidectomy for benign disease: A big data analysis. Clin Otolaryngol 2017;42:1259-66.

23. Vieira BL, Hernandez DJ, Qin C, et al. The impact of resident involvement on otolaryngology surgical outcomes. Laryngoscope 2016;126:602-7.

24. De la Garza Ramos R, Nakhla J, Nasser R, et al. The Impact of Hospital Teaching Status on Timing of

Cite this article as: Al-Qurayshi Z, Sullivan CB, Pagedar N, Randolph G, Kandil E. Prevalence of major structures injury in thyroid and neck surgeries: a national perspective. Gland Surg 2020;9(6):1924-1932. doi: 10.21037/gs-20-369
Intervention, Inpatient Morbidity, and Mortality After Surgery for Vertebral Column Fractures with Spinal Cord Injury. World Neurosurg 2017;99:140-4.

25. Advani V, Ahad S, Gonczy C, et al. Does resident involvement effect surgical times and complication rates during laparoscopic appendectomy for uncomplicated appendicitis? An analysis of 16,849 cases from the ACSNSQIP. Am J Surg 2012;203:347-351; discussion 351-2.

26. Wilkiemeyer M, Pappas TN, Giobbie-Hurder A, et al. Does resident post graduate year influence the outcomes of inguinal hernia repair? Ann Surg 2005;241:879-82; discussion 882-4.

27. Bresler AY, Bavier R, Kalyoussef E, et al. The "July effect": Outcomes in microvascular reconstruction during resident transitions. Laryngoscope 2020;130:893-8.

28. Wong A, Filimonov A, Lee YJ, et al. The Impact of Resident and Fellow Participation in Transsphenoidal Pituitary Surgery. Laryngoscope 2018;128:2707-13.

29. Baker AB, Ong AA, O'Connell BP, et al. Impact of resident involvement in outpatient otolaryngology procedures: An analysis of 17,647 cases. Laryngoscope 2017;127:2026-32.

30. Mahmoudi E, Lu Y, Chang SC, et al. The Associations of Hospital Volume, Surgeon Volume, and Surgeon Experience with Complications and 30-Day Rehospitalization after Free Tissue Transfer: A National Population Study. Plast Reconstr Surg 2017;140:403-11. 